\title{
Structural variability of the sub-surface cisternae in intact, isolated outer hair cells shown by fluorescent labelling of intracellular membranes and freeze-fracture
}

\author{
Andrew Forge ${ }^{\text {a }}$, Gary Zajic ${ }^{\text {b }}$, Lin Li ${ }^{\text {a }}$, Graham Nevill a and Jochen Schacht ${ }^{b}$ \\ a Institute of Laryngology and Otology, University College London, London, UK and ${ }^{b}$ Kresge Hearing Research Institute, University of Michigan, \\ Ann Arbor, Michigan, USA
}

(Received 16 April 1992; Revision received 3 August 1992; Accepted 13 August 1992)

\begin{abstract}
The intracellular membrane systems in intact, isolated outer hair cells were visualised using the fluorescent membrane probe $3,3^{\prime}$-dihexyloxacarbocyanine iodide $\left(\mathrm{DiOC}_{6}\right)$ and by freeze-fracture, and f-actin distribution was examined with rhodamine-phalloidin. $\mathrm{DiOC}_{6}$ stained the sub-surface cisternal membranes in the lateral wall and revealed a membrane system running in the centre of the cell from the nucleus to the sub-cuticular region. In optical sections of the lateral wall of fluorescently labelled cells, obtained by scanning laser confocal microscopy, the sub-surface membrane appeared as a fenestrated sheet or a fine network of tubules. Freeze-fracture replicas of rapidly-frozen, unfixed outer hair cells also showed the sub-surface membrane as a fenestrated sheet in some cells or as a network of tubules in others. These combined studies indicate that the interruptions within the cisternal membranes as seen in normal thin sections of outer hair cells are not fixation artefacts but may reflect the dynamic and plastic properties of this membrane system. Double staining of cells with rhodamine-phalloidin and DiOC 6 showed substantial co-localisation of intracellular membranes and f-actin. The results suggest there may be a continuous, dynamic endoplasmic reticulum system, forming a core in the centre of the cell, broadening in the subcuticular region and extending down the lateral wall, that may have a role in the turnover and distribution of cytoskeletal assemblies within the outer hair cell.
\end{abstract}

3,3'-Dihexyloxacarbocyanine iodide; Endoplasmic reticulum; Fluorescent membrane labelling; Hair cells; Lateral cisternae; Freeze-fracture

\section{Introduction}

In thin sections of the intact mammalian organ of Corti outer hair cells are seen to possess a series of flattened membranous sacs running parallel to and immediately inside the lateral plasma membrane from the level of the tight junction to the synaptic area of the cell (Spoendlin, 1957, Kimura, 1975). In freezefracture replicas, where membranes are exposed in face view, these 'sub-surface' or 'lateral' cisternae appear as a system of fenestrated membrane sheets or a network of tubules (Gulley and Reese, 1977; Saito, 1983; Forge, 1989; 1991). The discontinuities apparent in thin sections of the cisternal system, that give rise to its appearance as a series of separate sacs, therefore presumably represent the fenestrations in the membrane sheets.

Spoendlin (1957) originally argued that the discontinuities of the sub-surface cisternae normally seen in thin sections were artefacts arising post-mortem. Re-

Correspondence to: Andrew Forge, Institute of Laryngology and Otology, 330-332, Gray's Inn Road, London, WC1X 8EE, UK. Fax: (44) 71 837-9279. cent studies of outer hair cells prepared for thin section electron microscopy after isolation from the organ of Corti have tended to support this view as in these preparations only a few interruptions of the cisternal membranes were observed (Dieler et al., 1991; Evans, 1990). Consequently, it has been suggested that the discontinuities might arise as an artefactual distortion of cisternal membrane structure during fixation of the organ of Corti in situ (Evans, 1990).

The cisternal system is uniquely prominent and organised in outer hair cells, indicating that it probably plays an important role in this cell's specialised activities. It has been suggested that the sub-surface cisternae are important in separating a sub-plasmallemal space from the bulk of the cell cytoplasm allowing fluid movement within the lateral compartment to produce pressure gradients that result in cell elongation and contraction (Brownell, 1986). Alternatively, motile responses may be associated with actin which has been shown to be present in the lateral wall of the outer hair cell (Flock et al., 1986). Actin within a cortical cytoskeletal lattice structure (Holley and Ashmore, 1990) may have a role in fast motility, while actin more closely associated with the sub-surface cisternae could be important to slow motile responses (Dulon et al., 
1990; Holley and Kachar, 1992). Furthermore, alterations to the cisternae have been reported to be co-incident with the damage to outer hair cells induced by a variety of noxious agents (Slepecky et al., 1982; Dodson et al., 1982; Douek et al., 1983; McDowell et al., 1989; Karlsson et al., 1991), including damage resulting in elimination of motility (Dieler et al., 1991). For these reasons an accurate picture of the normal morphology of the cisternae in the living cell is of interest as this will assist in defining the function of the cisternal system in the normal and functionally impaired outer hair cell.

The membranes of the sub-surface cisternae show some structural characteristics similar to smooth endoplasmic reticulum (SER) (Forge, 1991), re-inforcing the commonly held view that the cisternal system is a specialised, organised form of SER ( $\mathrm{Lim}, 1986)$. It is possible to stain intracellular membranes in living cells with fluorescent lipophilic dyes that are able to penetrate the plasma membrane (Terasaki et al., 1984) and the cationic membrane probe $3,3^{\prime}$ dihexyloxacarbocyanine iodide $\left(\mathrm{DiOC}_{6}(3)\right)$ has been shown to be a useful label for SER networks (Terasaki and Reese, 1992). At low concentrations this dye is taken up by mitochondria, but at higher concentrations it then partitions also to the endoplasmic reticulum as well as other intracellular membranes such as the Golgi complex (Terasaki and Reese, 1992). Mitochondria can be distinguished by their morphology and their intensity of staining. For outer hair cells, thin sections indicate that there is relatively little Golgi and that this is confined to a restricted region in the sub-cuticular area of the cell. Consequently, it should be possible to identify the cisternal membranes in $\mathrm{DiOC}_{6}$-stained outer hair cells. We have therefore used this agent in conjunction with laser scanning confocal microscopy to determine the morphology of the cisternae in viable isolated outer hair cells. We have also freeze-fractured rapidly frozen, unfixed hair cells (Forge et al., 1991) as a means to assess the ultrastructural characteristics of the cisternae in similar preparations. With both these methods interruptions within the cisternal membrane sheets are identified.

\section{Methods}

\section{Cell preparation}

Cochleae were obtained from pigmented guinea pigs. Strips of organ of Corti were separated manually from the basilar membrane and hair cells isolated following incubation of the strips in $0.5 \mathrm{mg} \mathrm{ml}^{-1}$ collagenase (type IV; Sigma Chemicals) (Dulon et al., 1990). The cochleae were dissected, and the cells were maintained, in Hanks' Balanced Salt Solution (HBSS) buffered to pH 7.4 with $5 \mathrm{mM}$ HEPES. The osmolarity of all solutions was adjusted to $300( \pm 1)$ mOsm. The isolation procedures and all subsequent incubations and light microscopy were performed at room temperature.

\section{Fluorescence microscopy}

$\mathrm{DiOC}_{6}(3)$ (Molecular Probes, Eugene, OR) was prepared as a stock solution of $1 \mathrm{mg} \mathrm{ml}^{-1}$ in ethanol and diluted to $0.5 \mu \mathrm{g} \mathrm{ml}^{-1}$ in HBSS immediately before use. Strips of organ of Corti or isolated hair cells in HBSS were allowed to settle on to a glass slide or the surface of a plastic petri dish. The HBSS was withdrawn and replaced with the $\mathrm{DiOC}_{6}$ solution, and the cells incubated for $1 \mathrm{~min}$ before washing once in HBSS.

The preparations were examined either with a Zeiss Universal Microscope equipped with Nomarski differential interference contrast optics and for epifluorescence, or using a MRC Bio-RAD 600 laser scanning confocal unit assembled around a Nikon Diaphot TMD inverted microscope, with a $\times 60$ oil immersion objective N.A. 1.40. Fluorescent images were obtained using filters as for fluorescein: excitation $450-490 \mathrm{~nm}$; emission, $510 \mathrm{~nm}$ dichroic mirror, barrier filter $520 \mathrm{~nm}$.

In other isolated hair cell preparations a different probe, 1,1'-dioctadecyl-3,3,3',3'-tetramethylindocarbocyanine perchlorate (DilC ${ }_{18}$ (3)) (Molecular Probes) was used. This was prepared as a stock solution of 10 $\mathrm{mg} \mathrm{ml}{ }^{-1}$ in ethanol and diluted in HBSS to $12.5 \mu \mathrm{g}$ $\mathrm{ml}^{-1}$ before use. Preparations were incubated for $3 \mathrm{~h}$ at room temperature before examination by routine epifluorescence microscopy only using rhodamine-type filters: excitation, $510 \mathrm{~nm}$; emission, $580 \mathrm{~nm}$.

Double labelling of cells with $\mathrm{DiOC}_{6}$ and rhodamine-phalloidin to stain filamentous actin was also performed. Following incubation with $0.05 \%$ saponin for 1-2min, cells were stained for f-actin using rhodamine-phalloidin (Molecular Probes) at a 1:500 dilution from a stock of $200 \mathrm{IU} \mathrm{ml}^{-1}$ in methanol, for 15 $\mathrm{min}$. The cells were gently washed and incubated with DiOC $_{6}$ at $0.05 \mu \mathrm{g} \mathrm{ml}^{-1}$ for $1 \mathrm{~min}$ before another final wash. Cells were examined using routine epifluorescence.

\section{Freeze-fracture of unfixed cells}

Strips of organ of Corti or suspensions of isolated cells in 1-2 $\mu$ l HBSS were mounted between two thin copper plates and quick-frozen by plunging into rapidly stirred propane-isopentane (4:1) (Forge et al., 1991). The frozen samples were fractured by separating the sandwiches inside a freeze-fracture device (Balzers, Lichtenstein) and freeze-fracture replicas made using standard procedures (Forge et al., 1991; Forge, 1991).

\section{Thick-sections of metal impregnated cells}

The organisation of the cisternae in fixed preparations was assessed after heavy metal impregnation of 

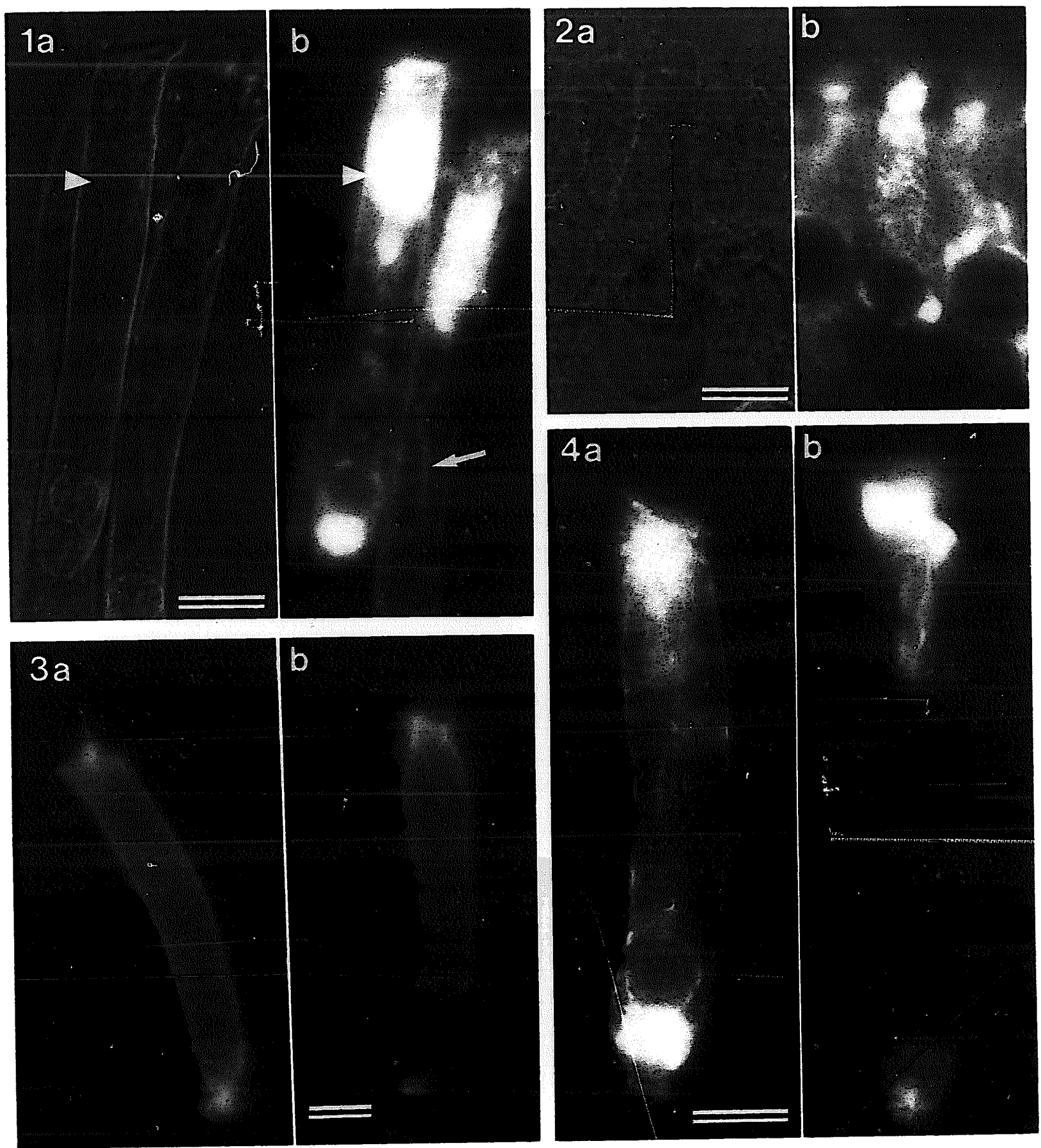

Fig. Fig. 1. Nomarski (a) and epifuorescew points to core of labelling in the centre of the cell. Note that the apical end of cell visible in (a) is not seen shows intense staining in (b) and arrow points to core of labelling in the centre of the

Fig. 2. Inner hair cell seen in Nomarski and epifluorescence images after DiOC $_{6}$ staining. The membrane systems seen in outer hair cells are not visible. In particular there is no staining in the lateral wall of the cell. Staining is predominantly of mitochondria. Scale bar $=10 \mu \mathrm{m}$.

Fig. 3. Two outer hair cells stained with DilC $_{18}$. This probe stains only the plasma membrane. The cell outline is clearly displayed but there is no obvious intracellular labelling. In (a) the stereocilia are clearly apparent; in (b) there is particularly intense staining in the position of the intercellular junction at the cell apex. Scale bar $=10 \mu \mathrm{m}$.

Fig. 4. Double staining with $\operatorname{DiOC}_{6}$ (a) and rhodamine-phalloidin (b). The intracellular membrane systems labelled in (a) closely match the locations where $\mathrm{f}$-actin is found in the cell in (b). Scale bar $=10 \mu \mathrm{m}$. 

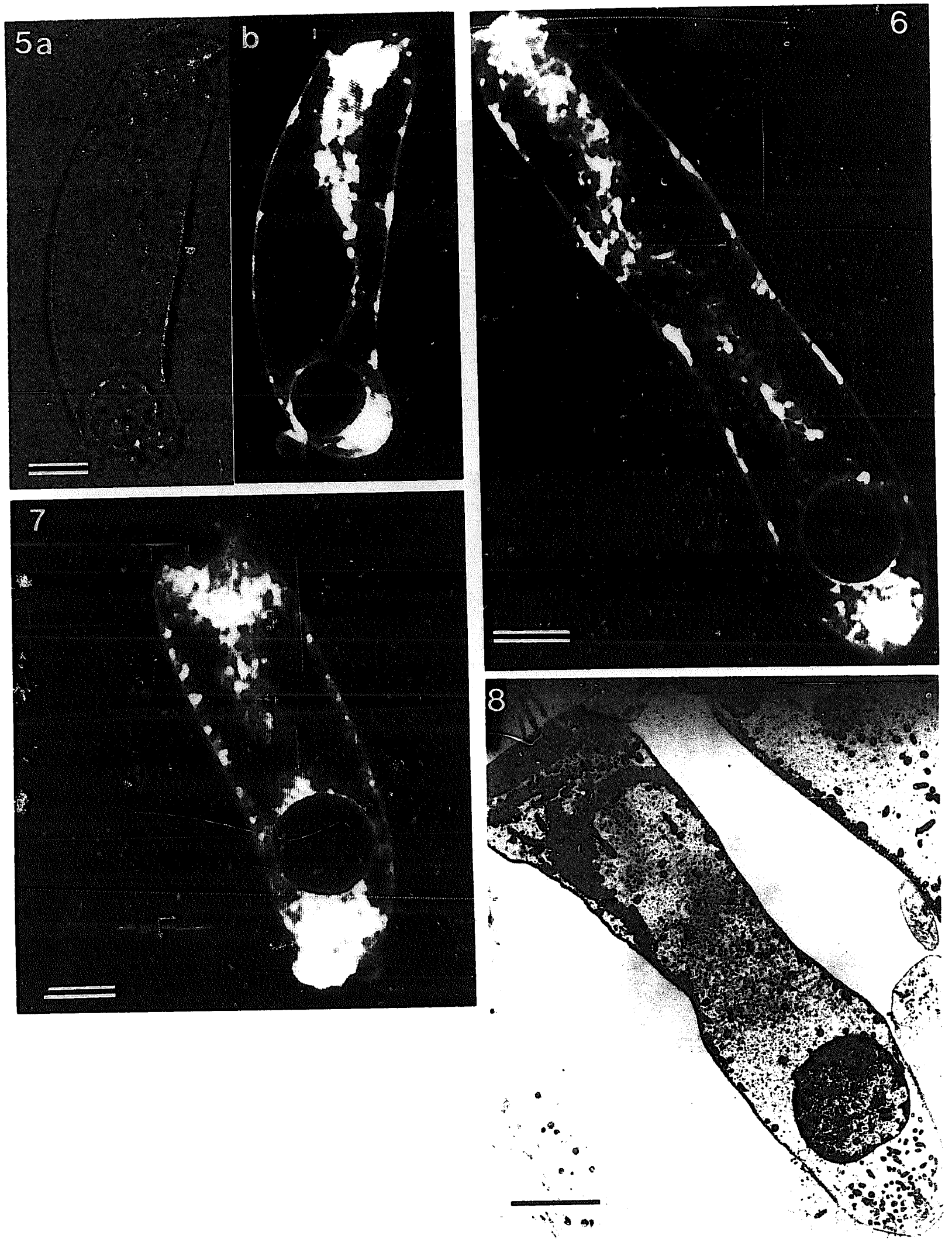

Fig. 5. Bright field (a) and laser scanning confocal fluorescent (b) images of a living short outer hair cell after DiOC 6 labelling. There is bright labelling in the lateral wall with mitochondria distinguishable as intensely stained puncta. A core of labelled membrane associated with mitochondria runs the entire length of the middle of the cell from the cuticular plate region to the nucleus. The apical end of the cell visible in the bright field image is not apparent in the fluorescently labelled cell. Scale bar $=5 \mu \mathrm{m}$.

Fig. 6. Confocal image of viable fluorescently-labelled cell. In this longer cell the membrane core is again evident, associated with mitochondria. Mitochondria are also seen below the nucleus and along the lateral wall. Scale bar $=5 \mu \mathrm{m}$. 
the intracellular membranes (Forge, 1982; Thiery and Rambourg, 1976). Following fixation of the cochleae in 2.5\% glutaraldehyde in $0.1 \mathrm{M}$ cacodylate buffer, the organ of Corti was dissected out and incubated in $2 \%$ aqueous uranyl acetate, $\mathrm{pH} 3.5$, for $1 \mathrm{~h}$ at $37^{\circ} \mathrm{C}$, washed in water then incubated for a further $1 \mathrm{~h}$ at $37^{\circ} \mathrm{C}$ in a lead-copper citrate solution. After this double metal impregnation, the tissue pieces were incubated in $1 \%$ aqueous $\mathrm{OsO}_{4}$ for $18 \mathrm{~h}$, dehydrated and embedded. Sections of 250-500 nm were cut and examined in a transmission electron microscope (JEOL 1200 EXII) operating at $120 \mathrm{Kv}$.

\section{Results}

\section{Routine epifluorescence microscopy}

Brief incubation of cells in DiOC 6 did not adversely affect outer hair cell viability as judged from the morphological characteristics of the cells examined by differential interference contrast (Fig. 1a) or bright field microscopy. However, the stain did appear to cause a more rapid deterioration of the cells than is normal. If examination of the cells was delayed for approx $15 \mathrm{~min}$ after addition of the stain a number of them showed some of the morphological changes previously described for degenerating hair cells (Zajic and Schacht, 1987). For this reason all studies were conducted within 15 min of addition DiOC $_{6}$.

In labelled cells examined by routine epifluorescence microscopy (Fig. 1b), there was clear labelling of the nuclear membrane and of Hensen's bodies as well as intense labelling below the cuticular plate and in the infranuclear region. DiOC $_{6}$ is taken up readily by mitochondria as well as intracellular membranes and these regions of intense staining correspond to those where, in thin sections, mitochondria are seen in abundance. There was also a core of stained membrane down the middle of the cell and intense staining along the entire lateral wall from just below the level of the tight junction. This represents labelling of the subsurface cisternae and their associated mitochondria. There was practically no staining of the apical end of the cell. Neither the cuticular plate region, within which there are no intracellular membranes, nor the plasma membrane either around the cuticular plate or of the cell apex and stereocilia could be discerned in routine fluorescence images (Fig. 1). This suggests there is probably very little contribution from labelling of the plasma membrane to the fluorescent image of the lateral wall of the cell. The observed labelling pattern was consistent for almost all the cells examined, both in strips of organ of Corti that had been separated only mechanically (Fig. 1) and in cells isolated after incubation in collagenase.

In inner hair cells (Fig. 2), again there was labelling of the nuclear membrane and, in addition, labelling distributed within the cell body, often in a punctate form indicating the locations of mitochondria. However, there was no obvious labelling of the lateral wall like that seen in outer hair cells, in line with the absence of an organised sub-surface cisternal system in inner hair cells. Indeed, whilst the lateral border of the cell could be identified in DIC images (Fig. 2a) it was not distinguishable in the fluorescent images (Fig. 2b). This emphasises that the fluorescent labelling along the lateral border of the OHC (Fig. 1b) is not an optical artefact nor the plasma membrane but represents staining of the OHC cisternal membranes.

In contrast to $\mathrm{DiOC}_{6}$, another fluorescent dye DilC $_{18}$, does not enter cells readily but is incorporated into the plasma membrane (Baumann et al., 1990). In outer hair cells incubated with DilC $_{18}$, there was no labelling of intracellular membranes even after $3 \mathrm{~h}$ but the cell outline and in particular the stereocilia were clearly defined (Fig. 3). In some cases the plasma membrane in the region of the tight junction surrounding the cuticular plate was differentiated and more intensely stained than the apical or baso-lat eral plasma membranes. The distinctive difference in the labelling patterns produced by the two probes again demonstrates that with $\mathrm{DiOC}_{6}$ most of the fluorescence in the lateral wall of the outer hair cell is from staining of the sub-surface intracellular membranes.

\section{Double labelling}

In cells stained with $\mathrm{DiOC}_{6}$ and rhodamine phalloidin, the membrane staining coincided with the actin labelling (Fig. 4). In particular, the central core of membrane staining closely corresponded to the actin staining in the infracuticular network in those cells where this structure was present. Also there was actin staining down the length of the lateral wall coincident with the $\mathrm{DiOC}_{6}$ labelling of the lateral cisternal membrane.

Fig 7. Confocal image of DiOC 6 -stained short outer hair cell. In this cell there is some staining of the plasma membrane around the cuticular plate and the cell apex, but this is clearly seen to be less intense than the staining in the lateral wall. The extent of the intracellular membrane plate and the cell apex, but the apical membrane at one side of the cuticular plate which is not labelled. Mitochondria are clearly differentiated. Scale bar $=5 \mu \mathrm{m}$.

Fig. 8. Thin section electron microscope image of an outer hair cell. This appears remarkably similar to the confocal images of the fluorescently labelled cells in Figs. 6 \& 7. Scale bar $=5 \mu \mathrm{m}$. 


\section{Confocal microscopy}

With the application of laser scanning confocal microscopy to $\mathrm{DiOC}_{6}$ stained cells it was possible to differentiate punctate, intense staining of mitochondria from continuous less-intense staining of intracellular membrane systems (Figs. 5, 6, 7). In the regions of intense staining at the cell apex and cell base it was possible to identify individual fluorescing mitochondria. The core of staining down the centre of the cell could be seen to run from immediately below the cuticular plate to the nuclear membrane. It was apparent in both short hair cells from the basal end of the cochlea (Fig. 5, 7) as well as in longer, more apical hair cells (Fig. 6). This membranous core appeared to consist of a complex of highly fluorescent mitochondria, and less intensely stained, continuous membrane. Memiranes extending up from the sub-cuticular region of high fluorescence to the cell apex round one side of
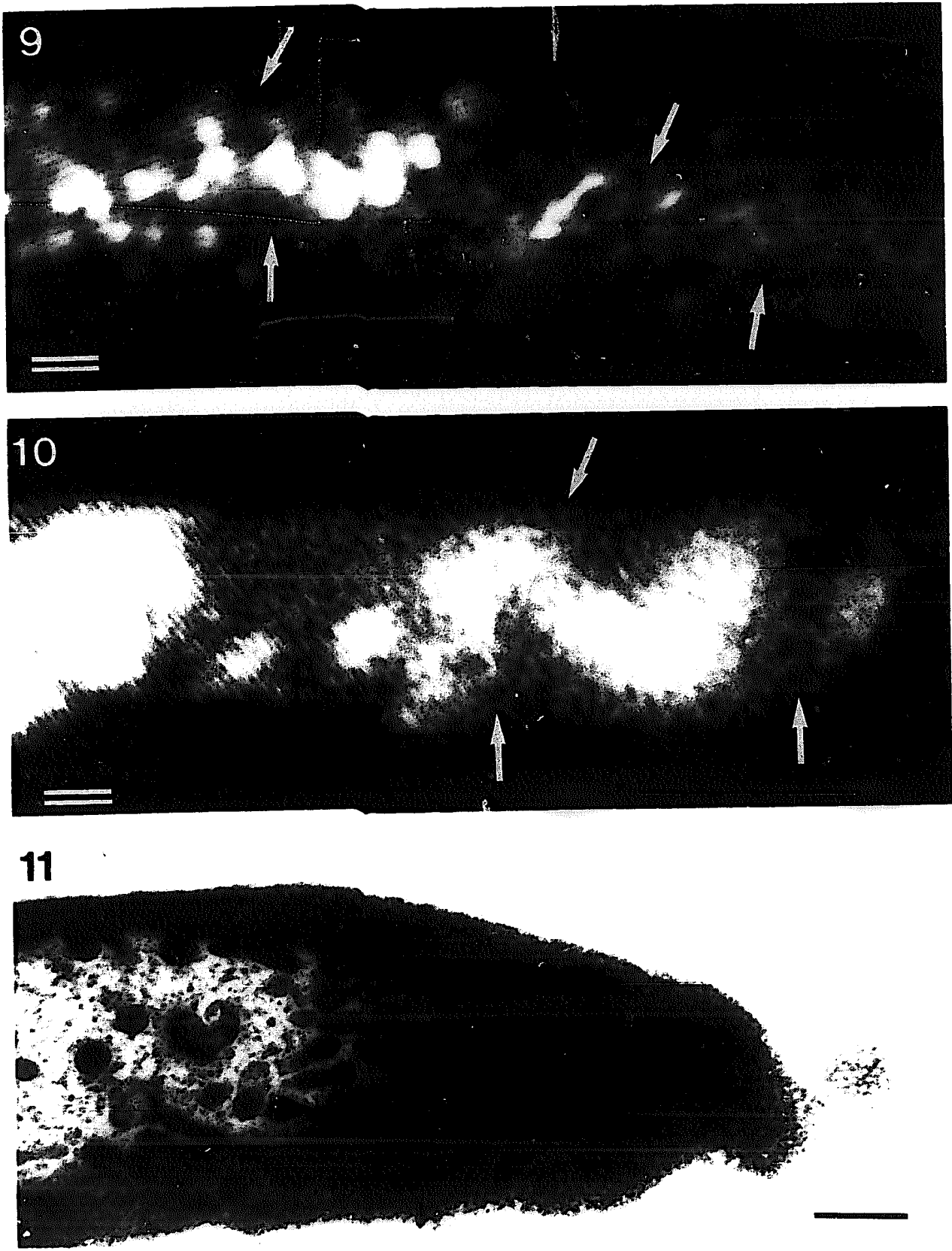

Fig. 9. Optical section $(0.5 \mu \mathrm{m})$ of the lateral wall of a living DiOC $_{6}$ stained outer hair cell. Discontinuities within the stained sheet of the cisternal membrane are apparent (arrows) Scale bar $=1 \mu \mathrm{m}$.

Fig. 10. Optical section of the OHC lateral wall in which the fluorescently labelled sub-surface cisternae appears as a network of tubules (arrows) Scale bar $=1 \mu \mathrm{m}$.

Fig. 11. Electron microscope section of the lateral wall cut at a similar thickness $(0.5 \mu \mathrm{m})$ to the optical sections in Figs. 9 \& 10 . The cisternal membranes appear as a fine meshwork of tubules. Scale bar $=1 \mu \mathrm{m}$. 
the cuticular plate were also labelled (Fig. 7). This delineated the cuticular plate itself which was not stained. Along the lateral wall staining was continuous and showed irregularly distributed intense thickenings indicating the position of the mitochondria. In most cells the apical end of the cell was not visible (Figs. 5 and 6) but in some (Fig. 7), the membrane around the cuticular plate and at the cell apex could be discerned, but only faintly. Where this occurred the relative thickness and intensity of staining of the membranes within the lateral wall vis a vis that of the plasma membrane was clearly apparent. The images show a striking resemblance to low power thin section electron microscope images of intact outer hair cells (Fig. 8).
To examine the morphology of the membranes in the lateral wall, optical sections through the cells were taken until a grazing section containing the lateral wall in face view was obtained. In these images (Figs. 9 and 10) the mitochondria immediately inside the subsurface cisternae produced a discontinuous intense fluorescence but the cisternal membranes were also evident as a less-intensely fluorescent, seemingly continuous, fluorescent sheet. In the areas of this sheet away from the mitochondria, careful examination revealed distinct interruptions in the form of unstained 'holes' (Fig. 9) or the sheet appeared as a network of stained elements (Fig. 10). This appearance of the lateral wall of the cell in unfixed viable cells is very similar to the
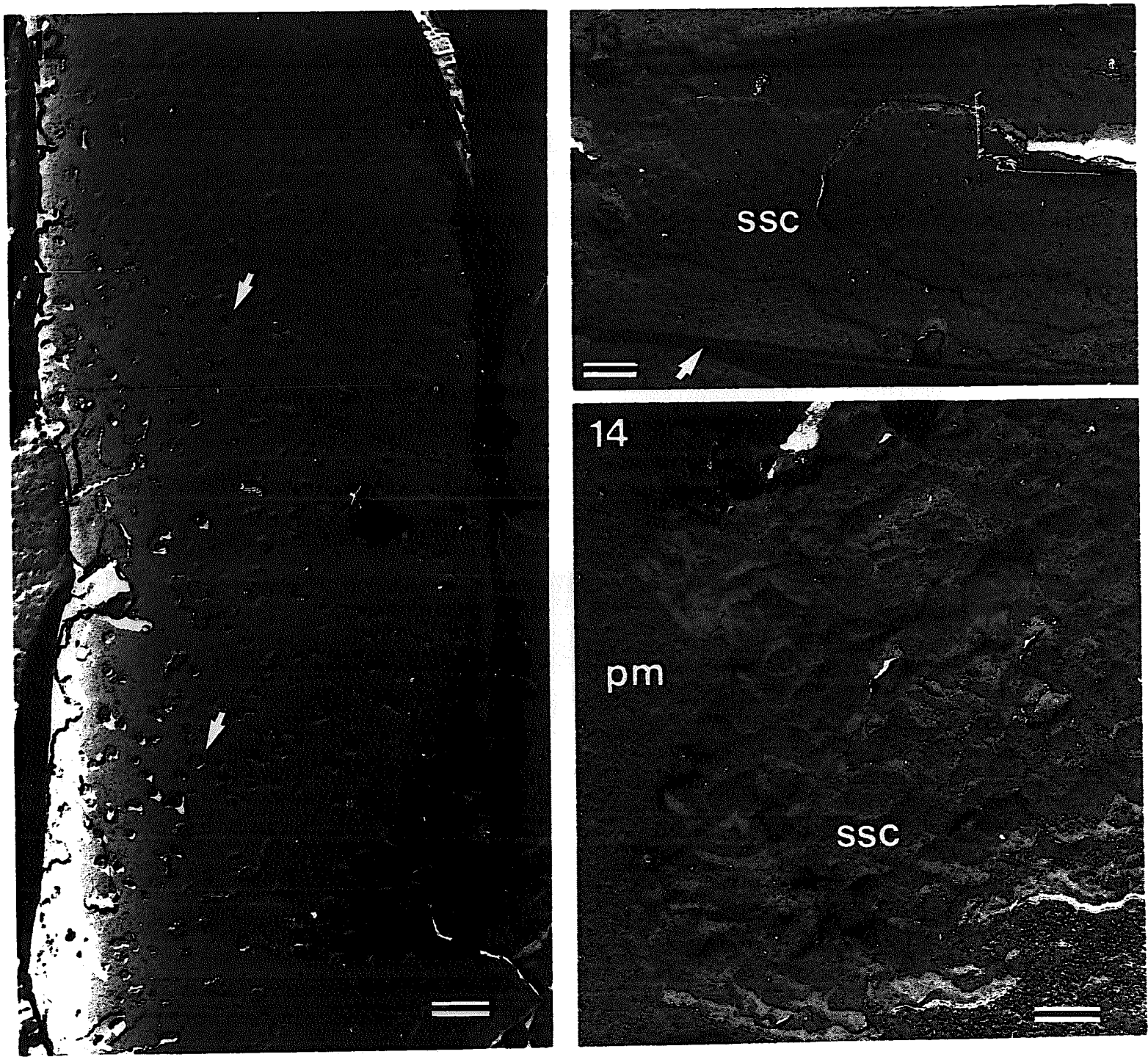

Fig 12 Freeze-fracture replica of unfixed, rapidly frozen cell. The cisternal membrane is revealed in face view and shows distinct fenestrations some of which are arrowed. Scale bar $=1 \mu \mathrm{m}$.

Fig. 13. Freeze-fracture of unfixed cell in which the sub-surface cisternae (ssc) show very few discontinuities. Arrow indicates the line of the cross-fractured plasma membrane. Scale bar $=0.5 \mu \mathrm{m}$.

Fig. 14. Freeze-fracture of unfixed cell in which the sub-surface cisternae appear as a system of tubules. pm=plasma membrane. Scale bar $=0.25 \mu \mathrm{m}$. 
morphology seen in 'thick' sections of fixed outer hair cells prepared for electron microscopy after impregnation of the intracellular membranes with heavy metals (Fig. 11). In these sections cut at a thickness similar to that of the optical sections of the unfixed cells examined by confocal microscopy, the cisternal membranes showed a network-like morphology.

\section{Freeze-fracture of unfixed cells}

Upon freeze-fracture, the membranes of the subsurface cisternae are extensively revealed in face view. In unfixed outer hair cells prepared by rapid freezing, discrete interruptions of the cisternal membrane sheet (fenestrations) were apparent (Fig. 12). However, variation between cells in the extent of fenestration was observed. In some long cells from the apical end of the cochlea, the cisternal membranes showed very few interruptions (Fig. 13) whilst in other cells the cisternae appeared as a network of membranous tubules (Fig. 14). These morphological characteristics are the same as those previously described for fixed outer hair cells (Forge, 1991).

\section{Discussion}

Two iriciependent procedures to examine unfixed outer hair cells, have demonstrated that the membrane sheets that form the sub-surface cisternae are interrupted to varying degrees by fenestrations. By light microscopy, cells with fenestrated cisternae appear healthy, and freeze-fracture shows the cisternae neither swollen nor vesiculated, features that have been suggested to be indications of trauma (Evans, 1990). Thus, the morphology of the cisternae shown here probably represents that of an undamaged cell and the images usually obtained in thin sections of the fixed organ of Corti, where the cisternae appear as a discontinuous series of elongated sacs, may not be artefacts of fixation.

However, the present results do show that there is considerable variabilty between cells in the extent to which their sub-surface membranes are fenestrated. Cells from the apical end of the cochlea show consistently less fenestration than their basal counterparts. It is conceivable that thin sections of apical hair cells may, on occasion, not reveal these infrequent discontinuities and the sub-surface cisternae may then appear continuous. In addition, after prolonged incubation of isolated outer hair cells separation of components within the plane of the cisternal membrane occurs and continuous, non-fenestrated aieas of membrane develop (Forge et al., 1991). These observations, and the fact that cisternal structure also changes under noxious insult, suggest that cisternal membrane morphology is quite plastic.
The sub-surface cisternae may also be part of a continuous membrane system that extends into a central core of endoplasmic reticulum. The pattern of membrane staining by $\mathrm{DiOC}_{6}$ is generally consistent with the organisation of intracellular membranes deduced from other techniques. Intraceliular membranes appear to be confined to particular regions of the cell: at the apical and basal ends, along the lateral wall and running up to the apical membrane in that small area where the cuticular plate is absent. Of particular interest is the fluorescent labelling of the central core of membrane, associated with numerous mitochondria at its upper end, running from the sub-cuticular region towards the nuclear membrane. Optical sectioning using the confocal microscope suggested that there is a significant continuity between the membrane systems in the different regions of the cell. Thus, there may be a continuous endoplasmic reticulum as a core in the centre of the cell, broadening in the sub-cuticular region and extending then down the lateral walls as the sub-surface membranes.

This distribution of the intracellular membranes corresponds closely with the regions of $\mathrm{f}$-actin location in the cell. The membrane core corresponds with the infracuticular network previously observed in the outer hair cells from the apical end of guinea pigs (Thorne et al. 1987), although the core is also present in hair cells from the basal end of the cochlea where an infracuticular network has not been identified. The infracuticular network is continuous with, though simpler in structure than, the cuticular plate (Forge and Zajic, unpublished observations). It also appears to have a structure very similar to that of the cortical cytoskeletal lattice (Holley and Ashmore, 1990). The possibility therefore arises that the intracellular membrane systems may be involved in the production and turnover of the cuticular plate and the cortical lattice.

The location and form of the central core of membrane closely matches the immunocytochemical distribution of tubulin in the outer hair cell (Steyger et al., 1989) suggesting that this membrane system is associated with microtubules which have been shown to be associated also with the inner aspect of the lateral cisternae. Microtubules are involved in the movement of intracellular organelles including endoplasmic reticulum membranes (Bridgman et al., 1986). If, indeed, there is continuity of the membrane systems, then it is possible that there is a continuous movement of the membrane from the centre of the cell to the periphery (or perhaps, vice versa) along pathways determined by the microtubules. This could provide a means for the production and turnover of cisternal membranes to which cytoskeletal structures could be attached and moved to their appropriate locations. Thus, the subsurface cisternae may be part of a continuous, dynamic intracellular network involved in the turnover and 
maintenance of structural and functional components of the cell.

\section{Acknowledgements}

This work was supported in part by a NATO Collaborative Research Award and NIH Programme Project Grant DC-00078. Dr Li was a WHO fellow.

\section{References}

Baumann, O., Kitazawa, T. and Somlyo, A.P. (1990) Laser confocal scanning microscopy of the surface membrane/T-tubule system and the sarcoplasmic reticulum in insect striated muscle stained with DilC $_{18}$ (3). J. Struct Biol. 105, 154-161.

Bridgman, P.C., Kachar, B. and Reese, T.S. (1986) The structure of cytoplasm in directly frozen cultured cells. II. Cytoplasmic domains associa:ed with organelle movements. J. Cell Biol. 102, 1510-1521.

Brownell, W.E. (1986) Outer hair cell motility and cochlear frequency selectivity. In: B.C.J. Moore and R.D. Patterson (Eds.), Auditory Frequency Selectivity, Plenum Press, New York, pp. 109-118.

Dieler R., Shehata-Dieler, W.E. and Brownell, W.E. (1991) Concomitant salicylate-induced alterations of outer hair cell subsurface cisternae and electromotility. J. Neurocytol. 20, 637-653.

Dodson, H.C., Bannister, L.H. and Douek, E.E. (1982) The effects of combined gentamicin and white noise on the spiral organ of young guinea pigs. Acta Otolaryngol. 94, 193-202.

Douek, E.E., Dodson, H.C. and Bannister, L.H. (1983) The effects of sodium salicylate on the cochlea of guinea pigs. J. Laryngol Otol. 97, 793-799.

Dulon, D., Zajic, G. and Schacht, J. (1990) Increasing intracellular free calcium induces circumferential contractions in isolated cochlear outer hair cells. J. Neurosci. 10, 1388-1397.

Evans, B.N. (1990) Fatal contractions: ultrastructural and electromechanical changes in outer hair cells following transmembrane stimulation. Hear. Res. 45, 265-282.

Flock, Å, Flock, B. and Ulfendahl, M. (1986) Mechanisms of movement in outer hair cells and a possible structural basis. Arch. Oto-Rhino-Laryngol. 243, 83-90.

Forge, A. (1982) A tubulo-cisternal endoplasmic reticulum system in the potassium transporting marginal cells of the stria vascularis and effects of the ototoxic diuretic ethacrynic acid. Cell Tissue Res. 226, 375-387.

Forge (1989) The lateral walls of inner and outer hair cells. In: J.P. Wilson and D.T. Kemp (Eds.), Cochlear Mechanisms, Plenum Publishing Corporation, New York, pp. 29-35.
Forge, A. (1991) Structural features of the lateral walls in mammalian cochlear outer hair cells. Cell Tissue Res. 265, 473-483.

Forge, A., Davies, S. and Zajic, G. (1991) Assessment of ultrastructure in isolated cochlear hair cells using a procedure for rapid freezing before freeze-fracture and deep-etching. J. Neurocytol. 20, 471-484.

Gulley, R.L. and Reese, T.S. (1977) Regional specialisation of the hair cell plasmalemma in the organ of Corti. Anat. Rec. 189, 109-124.

Holley, M.C. and Ashmore, J.F. (1990) Spectrin, actin and the structure of the cortical lattice in mammalian cochlear outer hair cells. J. Cell Sci. 96, 283-291.

Holley, M.C. and Kachar, B. (1992) The cortical cytoskeleton and cell shape changes in mammalian outer hair cells. In: Y. Cazals, L. Demany and K. Horner (Eds.), Auditory Physiology and Perception (Advances in the Biosciences, Vol. 83) Pergamon Press, London, pp. 27-33.

Karlsson, K.J., Flock, B. and Flock, Å. (1991) Ultrastructural changes in outer hair cells of the guinea pig cochlea after exposure to quinine. Acta Otolaryngol. 111, 500-505.

Kimura, R.S. (1975) The ultrastructure of the organ of Corti. Int Rev. Cytol. 42, 173-222

Lim, D.J. (1986) Functional structure of the organ of Corti: a review. Hear. Res. 22, 117-146.

McDowell, B., Davies, S. and Forge, A. (1989) The effect of gentamicin-induced hair cell loss on the tight junctions of the reticular lamina. Hear. Res. 40, 221-232.

Saito, K. (1983) Fine structure of the sensory epithelium of guinea pig organ of Corti: subsurface cisternae and lamellar bodies in the outer hair cells. Cell Tissue Res. 229, 467.-481.

Slepecky, N., Hamernik, R., Henderson, D. and Coling D. (1982) Correlation of audiometric data with changes in cochlear hair cell stereocilia resulting from impulse noise trauma. Acta Otolaryngol. 93, 329-340.

Spoendlin, H. (1957) Elecktronenmikroskopische Untersuchungen am Corti'schen Organ des Meerschweinchens. Prac. Otorhinolaryngol. 19, 192-234.

Steyger, P.S., Furness, D.N., Hackney, C.M. and Richardson, G.P. (1989) Tubulin and microtubules in cochlear hair cells: comparative inmurocytochemistry and uitrastructure. Hear. Res. 42, 1-16.

Terasaki, M. and Reese, T.S. (1992) Characterisation of endoplasmic reticulum by co-localisation of BiP and dicarbocyanine dyes. $\mathrm{J}$. Cell Sci. 101, 315-322.

Terasaki, M., Song, J.D., Wong, J.R., Weiss, M.J. and Chen, L.B. (1984) Localisation of endoplasmic reticulum in living and glutaraldehyde-fixed cells with fluorescent dyes. Cell 38, 101-108.

Thiery, G. and Rambourg, A. (1976) A new staining technique for studying thick sections in the electron microscope. J. Microsc. Biol. Cell 26, 103-106.

Thorne, P.R., Carlisle, L., Zajic, G., Schacht, J. and Altschuler, R.A. (1987) Differences in the distribution of F-actin in outer hair cells along the organ of Corti. Hear. Res. 30, 253-266.

Zajic, G. and Schacht, J. (1987) Comparison of isolated outer hair cells from five mammalian species. Hear. Res. 26, 249-256. 